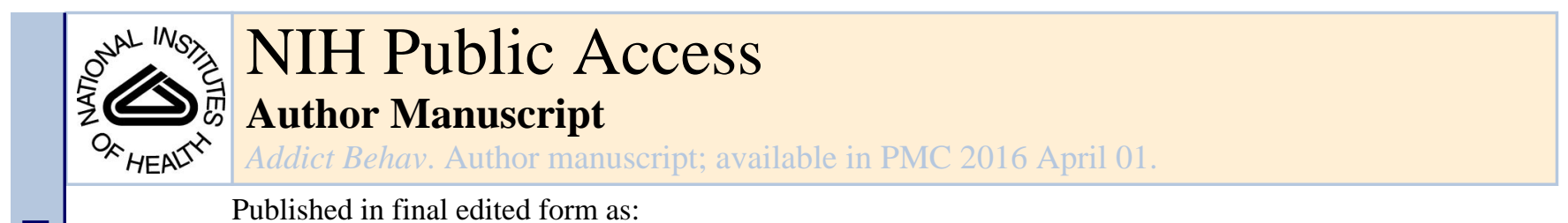

Published in final edited form as:

Addict Behav. 2015 April ; 43: 83-88. doi:10.1016/j.addbeh.2014.12.014.

\title{
Associations Between Childhood Trauma and Non-Fatal Overdose Among People Who Inject Drugs
}

\author{
Stephanie Lake, BHSc ${ }^{a, b}$, Kanna Hayashi, PhD ${ }^{a}$, M-J Milloy, PhD ${ }^{a, c}$, Evan Wood, MD, \\ $\mathbf{P h D}^{\mathrm{a}, \mathrm{c}}$, Huiru Dong, $\mathbf{M S c}^{\mathrm{a}}$, Julio Montaner, $\mathbf{M D}^{\mathrm{a}, \mathrm{c}}$, and Thomas Kerr, PhD ${ }^{\mathrm{a}, \mathrm{c}}$ \\ aBritish Columbia Centre for Excellence in HIV/AIDS, St. Paul's Hospital, 608-1081 Burrard \\ Street, Vancouver, BC, CANADA, V6Z 1 Y6 \\ bSchool of Population and Public Health, University of British Columbia, 5804 Fairview Avenue, \\ Vancouver, BC, CANADA, V6T 1 Z3 \\ 'Department of Medicine, University of British Columbia, St. Paul's Hospital, 608-1081 Burrard \\ Street, Vancouver, BC, CANADA, V6Z 1 Y6
}

\begin{abstract}
Introduction-Although people who inject drugs (IDU) remain at a high risk of accidental overdose, interventions that address overdose remain limited. Accordingly there is a continuing need to identify psychological and social factors that shape overdose risk. Despite being reported frequently among IDU, childhood trauma has received little attention as a potential risk factor for overdose. This study aims to evaluate relationships between non-fatal overdose and five forms of childhood maltreatment among a cohort of IDU in Vancouver, Canada.
\end{abstract}

Methods-Data was obtained from two prospective cohorts of IDU between December 2005 and May 2013. Multivariate generalized estimating equations (GEE) were used to explore relationships between five forms of childhood trauma and non-fatal overdose, adjusting for potential confounders.

Results-During the study period, 1697 IDU, including 552 (32.5\%) women, were followed. At baseline, 1136 (67.0\%) participants reported at least one form of childhood trauma, while 4-9\% reported a non-fatal overdose at each semi-annual follow-up. In multivariate analyses, physical [adjusted odds ratio (AOR): 1.36, 95\% confidence interval (CI): 1.08-1.71], sexual (AOR: 1.48,

(C) 2014 Elsevier Ltd. All rights reserved.

Send correspondence to: Thomas Kerr, PhD, Director, Urban Health Research Initiative, B.C. Centre for Excellence in HIV/AIDS, University of British Columbia, St. Paul's Hospital, 608-1081 Burrard Street, Vancouver, B.C., V6Z 1Y6 Canada, Tel: (604) 806-9116, Fax: (604) 806-9044, uhri-tk@cfenet.ubc.ca.

Contributors: SL designed the study and wrote the first draft of the manuscript; HD performed all statistical analyses; KH, MJM, EW, JM and TK provided input to the overall study design and revised the manuscript. All authors have read and approved the final manuscript.

Conflicts of Interest: All authors declare that they have no conflicts of interest.

Publisher's Disclaimer: This is a PDF file of an unedited manuscript that has been accepted for publication. As a service to our customers we are providing this early version of the manuscript. The manuscript will undergo copyediting, typesetting, and review of the resulting proof before it is published in its final citable form. Please note that during the production process errors may be discovered which could affect the content, and all legal disclaimers that apply to the journal pertain. 
CI: 1.17-1.87), and emotional abuse (AOR: 1.54, CI: 1.22-1.93) and physical neglect (AOR: 1.28, CI: 1.01-1.62) were independently associated with non-fatal overdose (all $p<0.05$ ).

Conclusions-Childhood trauma was common among participants, and reporting an experience of trauma was positively associated with non-fatal overdose. These findings highlight the need to provide intensive overdose prevention to trauma survivors and to incorporate screening for childhood trauma into health and social programs tailored to IDU.

\section{Keywords}

Childhood abuse; Childhood neglect; Childhood maltreatment; Injection drug use; Non-fatal overdose

\section{INTRODUCTION}

Overdose is a leading cause of premature mortality among people who inject drugs (IDU) (Evans et al., 2012; Gossop, Duncan, Treacy, \& Marsden, 2002; Mathers et al., 2013), while non-fatal overdose is a major contributor to morbidity among this population. The health consequences of non-fatal overdose are often severe and can include aspiration pneumonia, peripheral neuropathy, temporary limb paralysis, renal failure, rhabdomyolysis, seizures, and hypoxic brain injury (Darke \& Hall, 2003; Warner-Smith, Darke, \& Day, 2002). As lifetime prevalence of non-fatal overdose among IDU populations is typically around 45$60 \%$ (Kerr et al., 2007; Milloy et al., 2008), identifying its risk factors remains an important area of investigation.

In an effort to inform prevention strategies, research has focused on a variety of behavioural and sociodemographic risk factors specific to IDU (Darke, Williamson, Ross, \& Teesson, 2005; Fischer et al., 2004; Hakansson, Schlyter, \& Berglund, 2008; Havens et al., 2011;

Kerr et al., 2007; Milloy et al., 2008). Recent research has focused on various psychological risk factors for overdose, such as depression, posttraumatic stress disorder, and suicidal behaviour (Bohnert, Roeder, \& Ilgen, 2011; Bradvik, Frank, Hulenvik, Medvedeo, \& Berglund, 2007; Havens et al., 2011; Pabayo, Alcantara, Kawachi, Wood, \& Kerr, 2013; Tobin \& Latkin, 2003b). While evidence suggests that experiences of childhood trauma are strong predictors of depression and suicide in IDU (Marshall, Galea, Wood, \& Kerr, 2013; Walton et al., 2011), childhood trauma has received little attention as a risk factor for nonfatal overdose, despite being reported at a high rate within IDU and at-risk (i.e. substance abusing) populations (Kerr et al., 2009; Marshall et al., 2013; Medrano, Zule, Hatch, \& Desmond, 1999; Stoltz et al., 2007; Walton et al., 2011; Wang et al., 2010). For example, in a cohort of drug using youth in Vancouver, Canada, 26.8\%, 40.7\%, 49.6\%, 45.7\%, and $35.7 \%$ reported having experienced sexual abuse, physical abuse, emotional abuse, physical neglect, and emotional neglect, respectively (Kerr et al., 2009). Other research exploring the relationship between childhood trauma and overdose tends to be restricted to one type of trauma (e.g. sexual or physical abuse). To our knowledge, no previous research has assessed the full spectrum of childhood trauma - which includes emotional abuse, and physical and emotional neglect - using a standardized screening tool. Evidence suggests, however, that these more subtle forms of trauma can be strong predictors of various poor health and 
mental outcomes in IDU (Marshall et al., 2013; Stoltz et al., 2007) and other populations (Spertus, Yehuda, Wong, Halligan, \& Seremetis, 2003).

The present study therefore aims to examine the potential association between five forms of childhood trauma - physical, sexual, and emotional abuse, and physical and emotional neglect - and non-fatal overdose in an open prospective cohort of adult IDU in Vancouver, Canada.

\section{METHODS}

\section{1. Study Sample}

The Vancouver Injection Drug Users Study (VIDUS) and the AIDS Care Cohort to Evaluate Exposure to Survival Services (ACCESS) are ongoing open prospective cohorts of adult drug users recruited through self-referral and street outreach in Vancouver. The studies have been described in detail previously (Tyndall et al., 2003; Wood et al., 2008). Briefly, VIDUS enrolls HIV-negative persons who reported injecting an illicit drug at least once in the previous month; ACCESS enrolls HIV-positive persons who reported using an illicit drug other than marijuana in the previous month. For both cohorts, other eligibility criteria included being aged 18 years or older, residing in the greater Vancouver region and providing written informed consent. The study instruments and all other follow-up procedures for each study are essentially identical to allow for combined analyses.

At baseline and semi-annually, participants completed an interviewer-administered questionnaire eliciting sociodemographic data as well as information pertaining to drug use patterns, risk behaviors, and health care utilization. Nurses collected blood samples for HIV and hepatitis $\mathrm{C}$ serology and also provided basic medical care and referrals to appropriate health care services. Participants received a $\$ 20(\mathrm{CDN})$ honorarium for each study visit. The University of British Columbia/Providence Healthcare Research Ethics Board provided ethical approval for both studies.

\subsection{Measures}

The present analysis included participants who completed the baseline questionnaire between December 2005 and May 2013 and reported having injected drugs in the previous six months at baseline. The outcome of interest was non-fatal overdose in the previous six months. Since the goal was to capture overdoses from various substances, and poly-drug injection is a regular occurrence within the cohort (Kerr et al., 2007), we used a broad definition. Specifically, we asked study participants "In the last six months, have you ever overdosed by accident (i.e. where you had a negative reaction from using too much drugs)". This question was successfully pilot-tested during questionnaire development and has been used successfully in previous analyses (Milloy et al., 2008; Pabayo et al., 2013).

The main exposures of interest, the five forms of childhood trauma, were measured at baseline using the Childhood Trauma Questionnaire (CTQ): a 28-item validated instrument used to retrospectively assess childhood sexual, physical, and emotional abuse and physical and emotional neglect (Bernstein \& Fink, 1998). The CTQ has been used successfully in several studies of illicit drug-using populations (Bernstein \& Fink, 1998; Ducci et al., 2009; 
Lake et al., 2014; Walton et al., 2011), and has demonstrated good validity and reliability (Bernstein et al., 2003; Scher, Stein, Asmundson, McCreary, \& Forde, 2001). The questionnaire provides a score ranging from 5 to 25 for five subscales that correspond to each type of abuse and neglect. We used recommended and pre-determined cut-off scores to translate subscale scores into one of four levels of childhood trauma (Bernstein \& Fink, 1998): none or minimal (5-8), low to moderate (9-12), moderate to severe (13-15), and severe to extreme ( $>15)$. Consistent with previous studies (Lake et al., 2014; Stoltz et al., 2007), we collapsed these four trauma levels into two: none/low, and moderate/severe. We opted not to dichotomize variables into 'abuse' vs. 'no abuse' as such dichotomization has been shown to produce few significant findings in previous studies involving drug-using populations (Medrano, Hatch, Zule, \& Desmond, 2002).

Based on their known or a priori hypothesized relationship with both childhood trauma and non-fatal overdose, additional variables were included in the analysis: age (per year older), gender (male vs. female), ethnicity (Caucasian vs. other), living in unstable housing (yes vs. no), sex work involvement (yes vs. no), years injecting (per year longer), cocaine injection ( $\geq$ daily vs. <daily), heroin injection ( $\geq$ daily vs. <daily), crack smoking ( $\geq$ daily vs. <daily), benzodiazepine use (yes vs. no), heavy alcohol use ( $>14$ drinks per week or $>4$ drinks on one occasion for men, and $>7$ drinks per week or $>3$ drinks on one occasion for women (National Institute on Alcohol Abuse and Alcoholism); yes vs. no), requiring help injecting (yes vs. no), binge drug use (yes vs. no), injecting in public (yes vs. no), injected alone (yes vs. no), incarceration (yes vs. no), enrolling in addiction treatment (yes vs. no), being denied access to addiction treatment (yes vs. no), and HIV serostatus (positive vs. negative). All behavioural variables refer to the participant's behavior in the six months prior to the interview. Unless otherwise specified, variable definitions are consistent with those described in previous studies (Kerr et al., 2007; Kerr, Marsh, Li, Montaner, \& Wood, 2005; Stoltz et al., 2007).

\subsection{Analysis}

First, bivariate associations between all potential explanatory variables and non-fatal overdose measured at baseline were explored using Pearson's Chi-square (for binary measures) and Wilcoxon rank sum test (for continuous measures). As multiple measures for the dependent variable yielded serial measures for each subject, we used a generalized estimating equation (GEE) with logit link function and exchangeable correlation structure to determine whether childhood trauma was independently associated with non-fatal overdose through the entire follow-up period (Lee, Herzog, Meade, Webb, \& Brandon, 2007). This approach is often used in longitudinal studies involving a repeated measure binary dependent variable, and has been used successfully in studies of non-fatal overdose in IDU (Kerr et al., 2007; Milloy et al., 2008).

Based on previous studies using the CTQ (Stoltz et al., 2007), and in an effort to avoid issues of collinearity, we built five separate multivariate GEE models in which each of the five trauma types were considered as key independent variables of interest: physical abuse (model 1), sexual abuse (2), emotional abuse (3), physical neglect (4), and emotional neglect (5). Additional variables considered in each of the full models were those associated with 
non-fatal overdose at $p<0.10$ in bivariate GEE analysis, including: age, $\geq$ daily cocaine injection, $\geq$ daily heroin injection, $\geq$ daily crack smoking, heavy alcohol use, requiring help injecting, binge drug use, injecting in public, injecting alone, incarceration, and being denied access to addiction treatment. For each model, we used a stepwise approach to fit a series of reduced models (Maldondo \& Greenland, 1993). We compared the coefficient value associated with the main explanatory variable of interest (i.e., the CTQ subscale) in the full model to the coefficient value in each of the reduced models, and dropped the secondary variable associated with the smallest relative change. We continued this iterative process until the minimum change exceeded 5\%. All analyses were performed in SAS software version 8.0 (SAS, Cary, NC). All $p$-values are two-sided.

\section{RESULTS}

In total, 1697 participants completed a baseline survey in the study period and were included in the analysis, including $552(32.5 \%)$ women. The median age at baseline was 42.05 years (interquartile range [IQR]: 35.45 - 47.90). There were a total of 9,472 observations during the follow-up period, and the median number of study visits per participant was 5 (IQR: 29). A total of 570 overdoses were reported by 372 (21.9\%) participants over the study period. The proportion of participants reporting a recent overdose at a study follow-up visit ranged from $4.0 \%$ to $9.2 \%$ (median: $6.0 \%$ ). High rates of moderate-to-high levels of trauma were reported for all trauma categories, with emotional neglect being the most commonly experienced (49.4\%), followed by emotional abuse (44.3\%), physical abuse (33.9\%), physical neglect (30.4\%), and sexual abuse (30.0\%). The baseline characteristics of study participants stratified by non-fatal overdose are presented in Table 1.

Table 2, which includes all variables significant at $p<0.10$ in the bivariate analysis, summarizes the findings from all five multivariate GEE models. In multivariate analysis, after controlling for potential confounders, physical abuse (adjusted odds ratio [AOR]: 1.36, 95\% confidence interval [CI]: 1.08 - 1.71), sexual abuse (AOR: 1.48, CI: $1.17-1.87$ ), and emotional abuse (AOR: 1.54, CI: 1.22 - 1.93) were positively associated with non-fatal overdose, while physical neglect was marginally positively associated (AOR: 1.28, CI: 1.01 - 1.62). There was no statistically significant association between emotional neglect and non-fatal overdose (AOR: 0.99, CI: $0.79-1.24$ ).

\section{DISCUSSION}

We observed high rates of all forms of childhood trauma among IDU participating in this study. For each category, the prevalence in our sample was between $12-44 \%$, which was higher than the prevalence recorded in the general population (Scher, Forde, McQuaid, \& Stein, 2004). However, the presently recorded rates are similar to those found in other studies of drug using participants (Kerr et al., 2009; Marshall et al., 2013; Stoltz et al., 2007; Walton et al., 2011), emphasizing the overwhelming frequency of traumatic childhood experiences within this highly marginalized population. As expected, non-fatal overdose was experienced relatively frequently in our cohort, with approximately $22 \%$ of participants reporting at least one overdose throughout the study period. Physical, sexual, and emotional 
abuse, as well as physical neglect were all significantly and positively associated with nonfatal overdose, after adjusting for potential confounders.

To our knowledge, this is the first study to examine various forms of childhood trauma as risk factors for non-fatal overdose using a well-validated measure of childhood trauma. Our finding of a positive association between sexual abuse and non-fatal overdose is partially in agreement with another study of IDU, which detected this association, but only in the male portion of its sample (Braitstein et al., 2003). Of note, another study of opiate users found that a history of sexual and/or physical abuse was associated with non-fatal overdose in participants who had also attempted suicide (Maloney, Degenhardt, Darke, \& Nelson, 2009). Our finding regarding sexual abuse is particularly alarming given evidence that people who have experienced childhood sexual abuse are considerably more likely to die of overdose, compared to those without a history of sexual abuse (Cutajar et al., 2010).

Exposure to childhood trauma increases susceptibility to various mental health problems, such as anxiety (Spertus et al., 2003; Swanston et al., 2003), post-traumatic stress disorder (Spatz-Widom, 1999), and depression (Brown, Cohen, Johnson, \& Smailes, 1999; Walton et al., 2011), and previous research has consistently demonstrated that IDU with poor mental health are at an increased risk of non-fatal overdose (Havens et al., 2011; Pabayo et al., 2013; Tobin \& Latkin, 2003a). Given these well-documented relationships, our findings might be reflective of an attempt to cope with trauma-induced mental illness through intensive self-medication (Weiss, Griffin, \& Mirin, 1992). A theme repeatedly found in qualitative overdose literature is an ambivalent attitude towards death, which has been recorded among IDU survivors of traumatic life experiences, such as childhood abuse or neglect (Kerr, Small, Hyshka, Maher, \& Shannon, 2013; Moore, 2004). In these studies, those interviewed reported periods of increased drug consumption in order to eliminate or numb the negative emotions associated with traumatic memories. In doing so, individuals might be aware of the risk of overdose, but make no attempt to avoid or prevent it. While it is unclear whether this behaviour is inherently suicidal, it accompanies a previously established link between suicidal behaviour and childhood physical, sexual, and emotional abuse among substance users (Marshall et al., 2013).

In general, overdose prevention practices tend to focus on safe behavior at the individual level (e.g. instructions to inject with others and to sample a small dose of the drug first), with the assumption that awareness of prevention strategies should lead to an autonomous decision to avoid overdose (Moore, 2004). However, promoting these strategies has often proven to be ineffective or even counter-productive (Dietze, Jolley, Fry, Bammer, \& Moore, 2006; Kerr et al., 2013). The various psychological, social, and behavioural circumstances associated with surviving childhood abuse or trauma may disrupt the ability or desire to engage in overdose prevention efforts. For example, these experiences may interact with other risk factors (e.g., injection drug use, polydrug use, bingeing) to exacerbate the harmful drug-related outcomes (i.e., overdose). The current findings emphasize the importance of assessing the broader "risk environment" (Rhodes, 2002) in overdose prevention strategies, which includes screening for these adverse social exposures. While conventional overdose prevention strategies relying on education are shown to have had limited benefit, increasing coverage of naloxone distribution has considerable promise (Buxton, Purssell, Gibson, \& 
Tzemis, 2012; Compton, Volkow, Throckmorton, \& Lurie, 2013; Enteen et al., 2010; Oluwajenyo et al., 2014). Our results support that naloxone be made available to all IDU, and particularly survivors of childhood trauma. Programs frequently used by IDU, such as needle exchanges, supervised injecting sites, and addiction treatment services, should have well-established relationships with social and counseling services that have the capacity to address childhood trauma.

We note various limitations specific to this study. First, despite extensive recruitment efforts, VIDUS and ACCESS are not random samples and our results may not be generalizable to other IDU populations. Second, the self-reported nature of overdose may introduce the possibility of a bias; however, we feel that using this broad definition is advantageous in our setting, where poly-drug use is the norm and overdoses involving nonopioid substances are common. Third, our analysis was unable to assess depression, as this data was unavailable for half of the study period; however, we acknowledge the potential role depression may play in mediating this association, and it requires further investigation. Finally, self-reporting of data may elicit a response bias, including socially desirable responding and recall bias. In particular childhood trauma is susceptible to false negatives (Fergusson, Horwood, \& Woodward, 2000), and may be underreported in adulthood (Femina, Yeager, \& Lewise, 1990; Hardt \& Rutter, 2004).

This study aimed to investigate whether childhood trauma (physical, sexual, emotional abuse, and/or emotional and physical neglect) was associated with an increased risk of nonfatal overdose among a cohort of IDU. In addition to recording high rates of all forms of abuse and neglect, we found that non-fatal overdose was independently associated with being a survivor of childhood physical, sexual, and emotional abuse as well as physical neglect. Programs and strategies aimed at preventing overdose should take into account the heightened risk of overdose among the large population of IDU who have survived childhood abuse or neglect.

\section{Acknowledgments}

Role of Funding Source: This study is supported by the US National Institutes of Health (R01DA021525 and R01DA011591). Evan Wood is funded by the Canada Research Chairs Program through a Tier 1 Canada Research Chair in Inner City Medicine.

The authors thank the VIDUS and ACCESS participants for their contribution to the research, as well as current and past researchers and staff. We would also like to thank the administrative staff of the British Columbia Centre for Excellence in HIV/AIDS for their administrative assistance.

\section{References}

Bernstein, DP.; Fink, L. Childhood Trauma Questionnaire: A Retrospective Self-Report Manual. San Antonio, TX: Psychological Corp; 1998.

Bernstein DP, Stein JA, Newcomb MD, Walker E, Pogge D, Ahluvalia T, Zule W. Development and validation of a brief screening version of the Childhood Trauma Questionnaire. Child Abuse Negl. 2003; 27(2):169-190. [PubMed: 12615092]

Bohnert AS, Roeder KM, Ilgen MA. Suicide attempts and overdoses among adults entering addictions treatment: comparing correlates in a U.S. National Study. Drug and Alcohol Dependence. 2011; 119(1-2):106-112.10.1016/j.drugalcdep.2011.05.032 [PubMed: 21715108] 
Bradvik L, Frank A, Hulenvik P, Medvedeo A, Berglund M. Heroin addicts reporting previous heroin overdoses also report suicide attempts. Suicide and Life-Threatening Behavior. 2007; 37(4):475481. [PubMed: 17896887]

Braitstein P, Li K, Tyndall M, Spittal P, O’Shaughnessy MV, Schilder A, Schechter MT. Sexual violence among a cohort of injection drug users. Social Science and Medicine. 2003; 57(3):561569.10.1016/s0277-9536(02)00403-3 [PubMed: 12791497]

Brown J, Cohen P, Johnson JG, Smailes EM. Childhood abuse and neglect: specificity of effects on adolescent and young adult depression and suicidality. Journal of the American Academy of Child and Adolescent Psychiatry. 1999; 38(12):1490-1496. [PubMed: 10596248]

Buxton JA, Purssell R, Gibson E, Tzemis D. Increasing access to naloxone in BC to reduce opioid overdose deaths. British Columbia Medical Journal. 2012; 54(5):231-232.

Compton WM, Volkow ND, Throckmorton DC, Lurie P. Expanded access to opioid overdose intervention: research, practice, and policy needs. Annals of Internal Medicine. 2013; 158(1):65-66. [PubMed: 23277902]

Cutajar MC, Mullen PE, Ogloff JR, Thomas SD, Wells DL, Spataro J. Suicide and fatal drug overdose in child sexual abuse victims: a historical cohort study. Medical Journal of Australia. 2010; 192(4): 184-187. [PubMed: 20170453]

Darke S, Hall W. Heroin overdose: research and evidence-based intervention. Journal of Urban Health. 2003; 80(2):189-200. [PubMed: 12791795]

Darke S, Williamson A, Ross J, Teesson M. Non-fatal heroin overdose, treatment exposure and client characteristics: findings from the Australian treatment outcome study (ATOS). Drug Alcohol Rev. 2005; 24(5):425-432.10.1080/09595230500286005 [PubMed: 16298837]

Dietze P, Jolley D, Fry CL, Bammer G, Moore D. When is a little knowledge dangerous? Circumstances of recent heroin overdose and links to knowledge of overdose risk factors. Drug and Alcohol Dependence. 2006; 84(3):223-230.10.1016/j.drugalcdep.2006.02.005 [PubMed: 16542798]

Ducci F, Roy A, Shen PH, Yuan Q, Yuan NP, Hodgkinson CA, Goldman D. Association of substance use disorders with childhood trauma but not African genetic heritage in an African American cohort. American Journal of Psychiatry. 2009; 166(9):1031-1040.10.1176/appi.ajp. 2009.08071068 [PubMed: 19605534]

Enteen L, Bauer J, McLean R, Wheeler E, Huriaux E, Kral AH, Bamberger JD. Overdose prevention and naloxone prescription for opioid users in San Francisco. Journal of Urban Health. 2010; 87(6): 931-941.10.1007/s11524-010-9495-8 [PubMed: 20967505]

Evans JL, Tsui JI, Hahn JA, Davidson PJ, Lum PJ, Page K. Mortality among young injection drug users in San Francisco: a 10-year follow-up of the UFO study. American Journal of Epidemiology. 2012; 175(4):302-308.10.1093/aje/kwr318 [PubMed: 22227793]

Femina D, Yeager C, Lewise D. Child abuse: adolescent records vs. recall. Child Abuse Negl. 1990; 14(1):227-231. [PubMed: 2340430]

Fergusson DM, Horwood LJ, Woodward LJ. The stability of child abuse reports: a longitudinal study of the reporting behaviour of young adults. Psychological Medicine. 2000; 30

Fischer B, Brissette S, Brochu S, Bruneau J, El-Gabalawy R, Noel L, Baliunas D. Determinants of overdose incidents among illicit opioid users in 5 Canadian cities. CMAJ: Canadian Medical Association Journal. 2004; 171(3):235-239.10.1503/cmaj.1031416

Gossop M, Duncan S, Treacy S, Marsden J. A prospective study of mortality among drug misusers during a 4-year period after seeking treatment. Addiction. 2002; 97(1):39-47. [PubMed: 11895269]

Hakansson A, Schlyter F, Berglund M. Factors associated with history of non-fatal overdose among opioid users in the Swedish criminal justice system. Drug and Alcohol Dependence. 2008; 94(13):48-55.10.1016/j.drugalcdep.2007.10.014 [PubMed: 18082338]

Hardt J, Rutter M. Validity of adult retrospective reports of adverse childhood experiences: review of the evidence. Journal Child Psycho Psychiatry. 2004; 45(2):260-273.

Havens JR, Oser CB, Knudsen HK, Lofwall M, Stoops WW, Walsh SL, Kral AH. Individual and network factors associated with non-fatal overdose among rural Appalachian drug users. Drug and 
Alcohol Dependence. 2011; 115(1-2):107-112.10.1016/j.drugalcdep.2010.11.003 [PubMed: 21126831]

Kerr T, Fairbairn N, Tyndall M, Marsh D, Li K, Montaner J, Wood E. Predictors of non-fatal overdose among a cohort of polysubstance-using injection drug users. Drug and Alcohol Dependence. 2007; 87(1):39-45.10.1016/j.drugalcdep.2006.07.009 [PubMed: 16959438]

Kerr T, Marsh D, Li K, Montaner J, Wood E. Factors associated with methadone maintenance therapy use among a cohort of polysubstance using injection drug users in Vancouver. Drug and Alcohol Dependence. 2005; 80(3):329-335.10.1016/j.drugalcdep.2005.05.002 [PubMed: 15964714]

Kerr T, Small W, Hyshka E, Maher L, Shannon K. 'It's more about the heroin': injection drug users' response to an overdose warning campaign in a Canadian setting. Addiction. 2013; 108(7):12701276.10.1111/add.12151 [PubMed: 23551565]

Kerr T, Stoltz JA, Marshall BD, Lai C, Strathdee SA, Wood E. Childhood trauma and injection drug use among high-risk youth. Journal of Adolescent Health. 2009; 45(3):300-302.10.1016/ j.jadohealth.2009.03.007 [PubMed: 19699428]

Lake S, Wood E, Dong H, Dobrer S, Montaner J, Kerr T. The impact of emotional abuse on violence among people who inject drugs. Drug Alcohol Rev. 2014 In Press.

Lee JH, Herzog TA, Meade CD, Webb MS, Brandon TH. The use of GEE for analyzing longitudinal binomial data: a primer using data from a tobacco intervention. Addictive Behaviors. 2007; 32(1): 187-193.10.1016/j.addbeh.2006.03.030 [PubMed: 16650625]

Maldondo G, Greenland S. Simulation study of confounder-selection strategies. American Journal of Epidemiology. 1993; 138(11):923-936. [PubMed: 8256780]

Maloney E, Degenhardt L, Darke S, Nelson EC. Are non-fatal opioid overdoses misclassified suicide attempts? Comparing the associated correlates. Addictive Behaviors. 2009; 34(9):723729.10.1016/j.addbeh.2009.04.011 [PubMed: 19447563]

Marshall BD, Galea S, Wood E, Kerr T. Longitudinal associations between types of childhood trauma and suicidal behavior among substance users: a cohort study. American Journal of Public Health. 2013; 103(9):e69-75.10.2105/AJPH.2013.301257 [PubMed: 23865651]

Mathers BM, Degenhardt L, Bucello C, Lemon J, Wiessing L, Hickman M. Mortality among people who inject drugs: a systematic review and meta-analysis. Bulletin of the World Health Organization. 2013; 91(2):102-123.10.2471/BLT.12.108282 [PubMed: 23554523]

Medrano M, Hatch JP, Zule W, Desmond D. Psychological distress in childhood trauma survivors who abuse drugs. American Journal of Drug and Alcohol Abuse. 2002; 28(1):1-13. [PubMed: 11853127]

Medrano M, Zule W, Hatch JP, Desmond D. Prevalence of childhood trauma in a community sample of substance-abusing women. American Journal of Drug and Alcohol Abuse. 1999; 25(3):449462. [PubMed: 10473008]

Milloy MJ, Kerr T, Mathias R, Zhang R, Montaner JS, Tyndall M, Wood E. Non-fatal overdose among a cohort of active injection drug users recruited from a supervised injection facility. American Journal of Drug and Alcohol Abuse. 2008; 34(4):499509.10.1080/00952990802122457 [PubMed: 18584579]

Moore D. Governing street-based injecting drug users: a critique of heroin overdose prevention in Australia. Social Science and Medicine. 2004; 59(7):1547-1557.10.1016/j.socscimed.2004.01.029 [PubMed: 15246182]

National Institute on Alcohol Abuse and Alcoholism. Drinking Levels Defined. 2014. from http:// www.niaaa.nih.gov/alcohol-health/overview-alcohol-consumption/moderate-binge-drinking

Oluwajenyo B, Tzemis D, Al-Qutub D, Amlani A, Kesselring S, Buxton JA. A quantitative and qualitative evaluation of the British Columbia Take Home Naloxone program. CMAJ Open. 2014; 2(3):E153-E161.10.9778/cmajo.20140008

Pabayo R, Alcantara C, Kawachi I, Wood E, Kerr T. The role of depression and social support in nonfatal drug overdose among a cohort of injection drug users in a Canadian setting. Drug and Alcohol Dependence. 2013; 132(3):603-609.10.1016/j.drugalcdep.2013.04.007 [PubMed: 23647731]

Rhodes T. The 'risk environment': a framework for understanding and reducing drug-related harm. International Journal of Drug Policy. 2002; 13:85-94. 
Scher CD, Forde DR, McQuaid JR, Stein MB. Prevalence and demographic correlates of childhood maltreatment in an adult community sample. Child Abuse and Neglect. 2004; 28(2):167180.10.1016/j.chiabu.2003.09.012 [PubMed: 15003400]

Scher CD, Stein MB, Asmundson GJ, McCreary DR, Forde DR. The childhood trauma questionnaire in a community sample: psychometric properties and normative data. J Trauma Stress. 2001; 14(4):843-857.10.1023/A:1013058625719 [PubMed: 11776429]

Spatz-Widom C. Posttraumatic stress disorder in abused and neglected children grown up. American Journal of Psychiatry. 1999; 156:1223-1229. [PubMed: 10450264]

Spertus IL, Yehuda R, Wong CM, Halligan S, Seremetis SV. Childhood emotional abuse and neglect as predictors of psychological and physical symptoms in women presenting to a primary care practice. Child Abuse and Neglect. 2003; 27(11):1247-1258.10.1016/j.chiabu.2003.05.001 [PubMed: 14637300]

Stoltz JA, Shannon K, Kerr T, Zhang R, Montaner JS, Wood E. Associations between childhood maltreatment and sex work in a cohort of drug-using youth. Social Science and Medicine. 2007; 65(6):1214-1221.10.1016/j.socscimed.2007.05.005 [PubMed: 17576029]

Swanston HY, Plunkett AM, O'Toole BI, Shrimpton S, Parkinson PN, Oates RK. Nine years after child sexual abuse. Child Abuse and Neglect. 2003; 27(8):967-984.10.1016/ s0145-2134(03)00143-1 [PubMed: 12951144]

Tobin KE, Latkin CA. The relationship between depressive symptoms and nonfatal overdose among a sample of drug users in Baltimore, Maryland. Journal of Urban Health. 2003a; 80(2):220-229. [PubMed: 12791798]

Tobin KE, Latkin CA. The relationship between depressive symptoms and nonfatal overdose among a sample of drug users in Baltimore, Maryland. Journal of Urban Health. 2003b; 80(2):220 229.10.1093/jurban/jtg025 [PubMed: 12791798]

Tyndall MW, Currie S, Spittal P, Li K, Wood E, O’Shaughnessy MV, Schechter MT. Intensive injection cocaine use as the primary risk factor in the Vancouver HIV-1 epidemic. AIDS. 2003; 17(6):887-893.10.1097/01.aids.0000050859.71999.ae [PubMed: 12660536]

Walton G, Co SJ, Milloy MJ, Qi J, Kerr T, Wood E. High prevalence of childhood emotional, physical and sexual trauma among a Canadian cohort of HIV-seropositive illicit drug users. AIDS Care. 2011; 23(6):714-721.10.1080/09540121.2010.525618 [PubMed: 21390877]

Wang Z, Du J, Sun H, Wu H, Xiao Z, Zhao M. Patterns of childhood trauma and psychological distress among injecting heroin users in China. PloS One. 2010; 5(12):e15882.10.1371/ journal.pone.0015882 [PubMed: 21209959]

Warner-Smith M, Darke S, Day C. Morbidity associated with non-fatal heroin overdose. Addiction. 2002; 97(1):963-967. [PubMed: 12144598]

Weiss RD, Griffin ML, Mirin SM. Drug abuse as self-medication for depression: an empirical study. American Journal of Drug and Alcohol Abuse. 1992; 18(2):121-129. [PubMed: 1562010]

Wood E, Hogg RS, Lima VD, Kerr T, Yip B, Marshall BD, Montaner JS. Highly active antiretroviral therapy and survival in HIV-infected injection drug users. JAMA. 2008; 300(5):550-554.10.1001/ jama.300.5.550 [PubMed: 18677027] 
Table 1

Baseline characteristics associated with recent non-fatal overdose among IDU in Vancouver, Canada ( $\mathrm{n}=$ 1697).

\begin{tabular}{|c|c|c|c|c|}
\hline \multirow[t]{2}{*}{ Characteristic } & \multicolumn{2}{|c|}{ Non-fatal Overdose } & \multirow[b]{2}{*}{ Odds Ratio (95\% CI*) } & \multirow[b]{2}{*}{$p$ - value } \\
\hline & $\begin{array}{c}\text { Yes } \\
124(7.3 \%)\end{array}$ & $\begin{array}{l}\text { No } \\
1573(92.7 \%)\end{array}$ & & \\
\hline \multicolumn{5}{|l|}{$\mathrm{Age}^{+}$} \\
\hline \multirow[t]{2}{*}{ Median $\left(\mathrm{IQR}^{\S}\right)$} & 38.9 & 42.2 & \multirow[t]{2}{*}{-} & 0.038 \\
\hline & $(33.7-46.2)$ & $(35.6-48.0)$ & & \\
\hline \multicolumn{5}{|l|}{ Gender } \\
\hline Male & $79(63.7)$ & $1066(67.8)$ & $0.84(0.57-1.22)$ & 0.353 \\
\hline Female & $45(36.3)$ & $507(32.2)$ & & \\
\hline \multicolumn{5}{|l|}{ Ethnicity } \\
\hline Caucasian & $88(71.0)$ & $956(60.8)$ & $1.62(1.08-2.43)$ & 0.019 \\
\hline Other & $35(28.2)$ & $616(39.2)$ & & \\
\hline \multicolumn{5}{|c|}{ Unstable housing $^{\dagger}$} \\
\hline Yes & $92(74.2)$ & $1093(69.5)$ & $1.29(0.85-1.97)$ & 0.235 \\
\hline No & $31(25.0)$ & $475(30.2)$ & & \\
\hline \multicolumn{5}{|l|}{ Sex work ${ }^{\dagger}$} \\
\hline Yes & $22(17.7)$ & $231(14.7)$ & $1.28(0.79-2.08)$ & 0.310 \\
\hline No & $99(79.8)$ & $1334(84.8)$ & & \\
\hline \multicolumn{5}{|c|}{ Daily cocaine injection ${ }^{\dagger}$} \\
\hline Yes & $21(16.9)$ & $153(9.7)$ & $1.89(1.15-3.11)$ & 0.011 \\
\hline No & $103(83.1)$ & $1419(90.2)$ & & \\
\hline \multicolumn{5}{|c|}{ Daily heroin injection ${ }^{\dagger}$} \\
\hline Yes & $53(42.7)$ & $419(26.6)$ & $2.06(1.42-2.99)$ & $<0.001$ \\
\hline No & $71(57.3)$ & $1154(73.4)$ & & \\
\hline \multicolumn{5}{|c|}{ Daily crack smoking } \\
\hline Yes & $63(50.8)$ & $621(39.5)$ & $1.58(1.10-2.28)$ & 0.014 \\
\hline No & $61(49.2)$ & $951(60.5)$ & & \\
\hline \multicolumn{5}{|c|}{ Heavy alcohol use } \\
\hline Yes & $22(17.7)$ & $251(16.0)$ & $1.14(0.70-1.83)$ & 0.605 \\
\hline No & $102(82.3)$ & $951(60.5)$ & & \\
\hline \multicolumn{5}{|c|}{ Require help injecting ${ }^{\dagger}$} \\
\hline Yes & $45(36.3)$ & $364(23.1)$ & $1.85(1.26-2.72)$ & 0.002 \\
\hline No & $78(62.9)$ & $1168(74.3)$ & & \\
\hline \multicolumn{5}{|c|}{ Injecting in public } \\
\hline Yes & $76(61.3)$ & $567(36.0)$ & $2.80(1.92-4.08)$ & $<0.001$ \\
\hline No & $48(38.7)$ & $1003(63.8)$ & & \\
\hline
\end{tabular}




\begin{tabular}{|c|c|c|c|c|}
\hline \multirow[t]{2}{*}{ Characteristic } & \multicolumn{2}{|c|}{ Non-fatal Overdose } & \multirow[b]{2}{*}{ Odds Ratio (95\% CI*) } & \multirow[b]{2}{*}{$p$ - value } \\
\hline & $\begin{array}{c}\text { Yes } \\
124(7.3 \%)\end{array}$ & $\begin{array}{l}\text { No } \\
1573(92.7 \%)\end{array}$ & & \\
\hline \multicolumn{5}{|l|}{ Injecting alone } \\
\hline Yes & $104(83.9)$ & $1088(69.2)$ & $1.75(1.06-2.90)$ & 0.027 \\
\hline No & $19(15.3)$ & $348(22.1)$ & & \\
\hline \multicolumn{5}{|l|}{ Incarceration } \\
\hline Yes & $37(29.8)$ & $259(16.5)$ & $2.20(1.46-3.31)$ & $<0.001$ \\
\hline No & $85(68.5)$ & $1309(83.2)$ & & \\
\hline \multicolumn{5}{|l|}{ Denied treatment } \\
\hline Yes & $14(11.3)$ & $78(5)$ & $2.52(1.38-4.60)$ & 0.002 \\
\hline No & $106(85.5)$ & 1489 (94.7) & & \\
\hline \multicolumn{5}{|l|}{ HIV serostatus } \\
\hline Positive & $45(36.3)$ & $602(38.3)$ & $0.92(0.63-1.34)$ & 0.662 \\
\hline Negative & $79(63.7)$ & $971(61.7)$ & & \\
\hline \multicolumn{5}{|l|}{ Physical abuse } \\
\hline Mod/Heavy & $53(42.7)$ & $522(33.2)$ & $1.52(1.04-2.21)$ & 0.029 \\
\hline Low/None & $67(54.0)$ & $1000(63.6)$ & & \\
\hline \multicolumn{5}{|l|}{ Sexual abuse } \\
\hline Mod/Heavy & $48(38.7)$ & $461(29.3)$ & $1.56(1.06-2.28)$ & 0.022 \\
\hline Low/None & $72(58.1)$ & $1078(68.5)$ & & \\
\hline \multicolumn{5}{|l|}{ Emotional abuse } \\
\hline Mod/Heavy & $61(49.2)$ & $690(43.9)$ & $1.31(0.90-1.91)$ & 0.155 \\
\hline Low/None & $56(45.2)$ & $832(52.9)$ & & \\
\hline \multicolumn{5}{|l|}{ Physical neglect } \\
\hline Mod/Heavy & $40(32.3)$ & $475(30.2)$ & $1.18(0.79-1.76)$ & 0.412 \\
\hline Low/None & $76(61.3)$ & $1066(67.8)$ & & \\
\hline \multicolumn{5}{|c|}{ Emotional neglect } \\
\hline Mod/Heavy & $58(46.8)$ & $781(49.7)$ & $0.96(0.66-1.40)$ & 0.844 \\
\hline Low/None & $58(46.8)$ & $752(47.8)$ & & \\
\hline
\end{tabular}

95\% CI $=95 \%$ Confidence interval

${ }^{\dagger}$ Denotes events in the previous six months

Wilcoxon rank sum test was used for continuous variables

${ }_{\mathrm{IQR}}=$ Interquartile range

Note: Not all cells add up to 1697 as participants may choose not to answer sensitive questions 


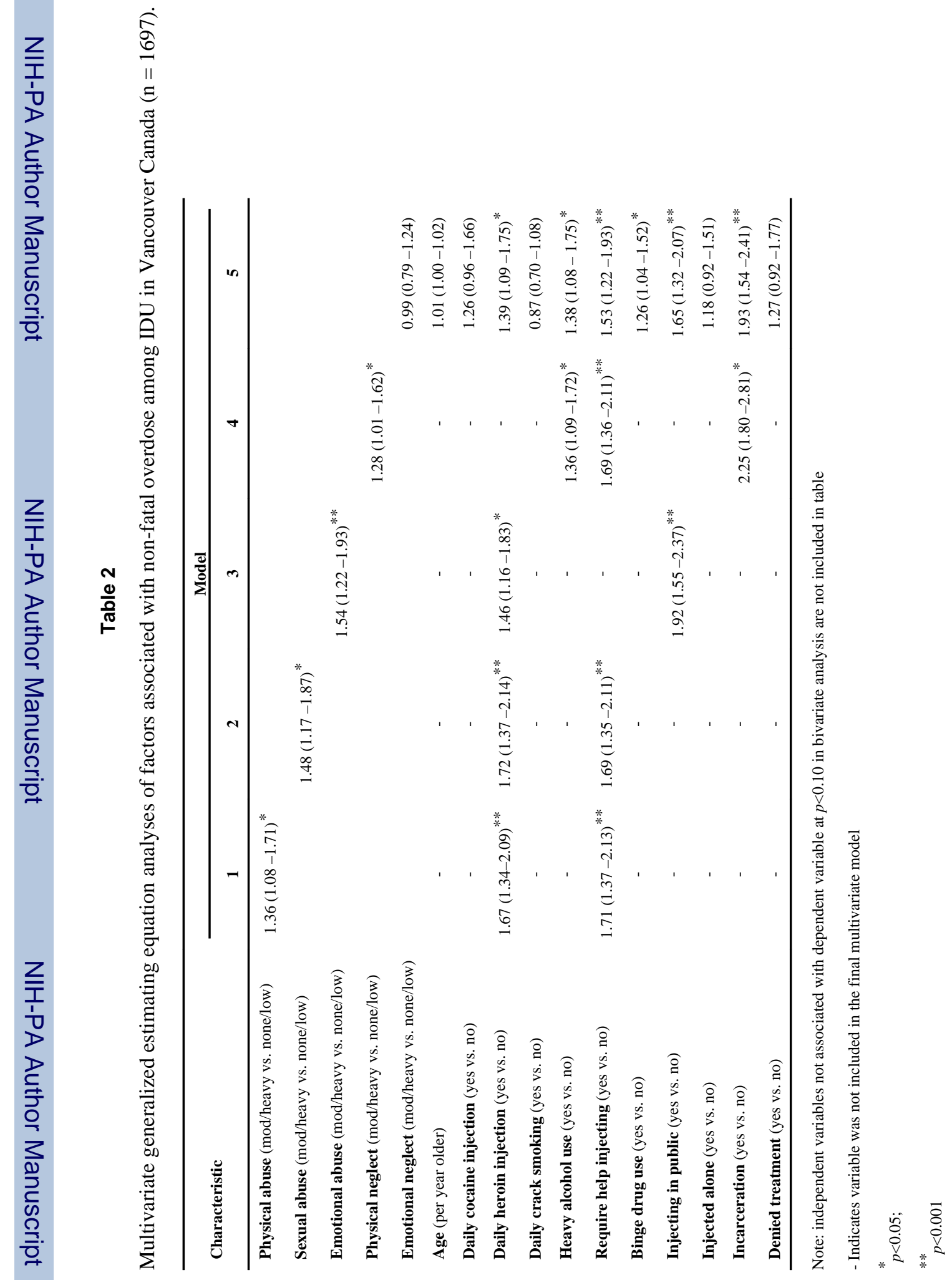

Addict Behav. Author manuscript; available in PMC 2016 April 01. 